\title{
Electrokinetic remediation of perchloroethylene-contaminated soil
}

\author{
M. Gholami $\cdot$ D. Yousefi Kebria $\cdot$ M. Mahmudi
}

Received: 29 August 2013/Revised: 5 February 2014/ Accepted: 12 March 2014/Published online: 23 April 2014

(C) Islamic Azad University (IAU) 2014

\begin{abstract}
One large group of persistent and toxic contaminants is the hydrophobic organic contaminants. Among them, perchloroethylene (PCE) has been recognized as a representative group of these pollutants with low solubility. This study reports on the effects of electrokinetic remediation with non-ionic surfactant on PCEcontaminated soil. The performance of electrokinetic process was investigated in the treatment of clay soil that artificially contaminated with two levels: 10,000 and $30,000 \mathrm{mg} / \mathrm{kg}$ PCE and $0.33 \mathrm{~g} / \mathrm{kg}$ Triton X-100. A DC power supply with electric voltage $(1 \mathrm{~V} / \mathrm{cm})$ was used for 8-16 days. A negatively charged soil surface resulted in a more negative zeta potential and greater electroosmotic flow toward the cathode. The PCE was measured after extraction using $n$-hexane and analyzed by Fourier transform infrared spectroscopy instrument. The water content of soil was kept $25 \%$ (w/w). Results were shown that PCE removal efficiency achieved was 74 and $89 \%$ for 10,000 and $30,000 \mathrm{mg} / \mathrm{kg} \mathrm{PCE}$, respectively, for 16 days. Therefore, in this study, the integration of electrokinetic with non-ionic surfactant as a hybrid method was most effective for the remediation of PCE-contaminated soils.
\end{abstract}

M. Gholami $(\bowtie) \cdot$ D. Yousefi Kebria

Babol Noshirvani University of Technology, P.O. Box 484,

Babol, Iran

e-mail: gholamimaedeh@yahoo.com

M. Mahmudi

Mazandaran Agricultural and Natural Resources Research

Center, P.O. Box 48175-556, Sari, Iran
Keywords Soil - Electroosmosis - Direct current electric voltage $\cdot$ Non-ionic surfactant $\cdot$ Perchloroethylene

\section{Introduction}

The contamination of soil with perchloroethylene (PCE) and trichloroethylene (TCE) is widespread (Arjoon et al. 2013; Adams et al. 2013). PCE is a halogenated aliphatic organic compound which, due to its unique properties and solvent effects, has been widely used in industrial degreasing agent and also used as a solvent in dry cleaning and an ingredient in paints, inks, and disinfectants. PCE, TCE, and trichloroethane (TCA) are the most frequently detected volatile organic chemicals (VOCs) in soil and groundwater in the United States (Fischer et al. 1987). Reductive dehalogenation of PCE through natural or induced mechanisms may result in production of vinyl chloride (VC) which, in contrast to PCE, is a known carcinogen (Freedman and Gossett 1989). Important considerations derived from physical and chemical properties of PCE are presented in Table 1.

Many techniques exist for the remedial treatment of contaminated land including isolation, immobilization, toxicity reduction, physical separation, and extraction. Few remediation technologies are available for the removal of chlorinated hydrocarbon from rather low hydraulic permeability media, such as clay. The electrokinetic remediation is a relatively new method, which involves passing a low electrical current between electrode pairs imbedded in the ground for the removal of subsurface contaminants via electrophoresis, electroosmosis, and electromigration (Chung and Lee 2007; Acar and Alshawabkeh 1993; Zhang et al. 2013). This technology is particularly effective in low-permeability soils, 
Table 1 Physical and chemical characteristics of perchloroethylene

\begin{tabular}{ll}
\hline Parameters & Amount \\
\hline Molecular formula & $\mathrm{C}_{2} \mathrm{Cl}_{4}$ \\
Molar mass & $165.83 \mathrm{~g} / \mathrm{mol}$ \\
Density & $1.622 \mathrm{~g} / \mathrm{cm}^{3}$ \\
Melting point & $254 \mathrm{~K}$ \\
Boiling point & $394 \mathrm{~K}$ \\
Solubility in water $\left(20^{\circ} \mathrm{C}\right)$ & $150 \mathrm{mg} / \mathrm{L}$ \\
\hline
\end{tabular}

where hydrodynamic techniques would not be suitable (Yeung et al. 1996; Reddy and Saichek 2003). The fundamental contaminant removal mechanisms of electrokinetic extraction are electroosmosis and ionic migration (Yeung and Corapcioglu 1994).

When a direct current (DC) electric field is imposed on a wet mass of soil, pore fluid is moved from one electrode toward the other by electroosmosis due to the interaction between the diffuse double layers existing at the soil particle/fluid interface and the pore fluid (Yeung and Corapcioglu 1994; Hunter 1981; Mitchell 1993). In this process, the major mechanisms leading to the removal of contaminants from the soil include the advection of electroosmosis flow driven under an electrical field, the movement of $\mathrm{H}^{+}$ions generated from $\mathrm{H}_{2} \mathrm{O}$ electrolysis at the anode advancing through soil toward the cathode (Fig. 1), and the migration of charged ions toward the opposite electrodes (Weng et al. 2000). Electrokinetic (EK) process is capable of removing non-polar chlorinated hydrocarbons, such as PCE, in spite of the lack of enhancement of ion migration in the treatment performance (Weng et al. 2000; Bruell et al. 1992; Ho et al. 1999; Yang and Long 1999).

In this study, the effectiveness of using an EK process integrated with non-ionic surfactant on remediation of PCE-contaminated clay soil was investigated. This study was carried out in environment laboratory of Babol Noshirvani University of Technology, in 2012.

\section{Materials and methods}

Soil

The soil used in the experimental portion of this study was a clean soil taken from a site at the Babol Noshirvani University of Technology, from a depth of 20 to $30 \mathrm{~cm}$ below ground. It was classified using a range of tests, which are described below. Table 2 shows the physical characteristics of the soils used in this study. In order to provide a uniform size distribution, the soil aggregates were broken by a wooden mallet, air-dried, and sieved in a 2-mm mesh and was then used in all experiments. The soil was spiked artificially with PCE at concentrations of about 10000 and $30000 \mathrm{mg} / \mathrm{kg}$ PCE dry soil (1, $3 \%$ by weight) to selectively higher than standard concentration of pollution (Freedman and Gossett 1989; Gan et al. 2009). The PCE-spiked soil, $1 \%($ Ek-1 \%) and $3 \%$ (Ek-3\%) contamination, was prepared by adding $1 \mathrm{~kg}$ of soil into a bottle containing 6 and $18 \mathrm{ml}$ of PCE reagent, respectively, and $150 \mathrm{ml}$ acetone solution.

\section{Experiment setup}

The soils ( $2.2 \mathrm{~kg}$ dry soil per reactor) were packed into plexy glass reactor (height $10.5 \mathrm{~cm}$, length $16 \mathrm{~cm}$, width $15 \mathrm{~cm}$, thickness $0.5 \mathrm{~cm}$ ) and mixed with $0.5 \mathrm{~g} / \mathrm{kg}$ Triton X-100 (surfactant) per kg soil, in solution and homogenized. Each pot was divided into three chambers and labeled as anode region $(0-5 \mathrm{~cm}$ from the anode), middle region $(5-11 \mathrm{~cm}$ from the anode), and cathode region (11-16 cm from the anode) along with the reactor length.

The electrokinetic remediation system included a pair of electrodes, with a DC power supply of $0-60 \mathrm{~V}$ (Fig. 2) . Graphite electrodes (length $13.5 \mathrm{~cm}$, width $10 \mathrm{~cm}$, thickness $0.5 \mathrm{~cm}$ ) were vertically inserted into the soil at the both sides of experimental reactors, which were used as electrodes because of their low cost, inert, availability, and high corrosion resistance in low-intensity electric current. Type of electrodes used does not have effect on intensity of electric current during the experiment (Khodadadi et al. 2011; Gholami and Yousefi
Fig. 1 Schematic of EK remediation process

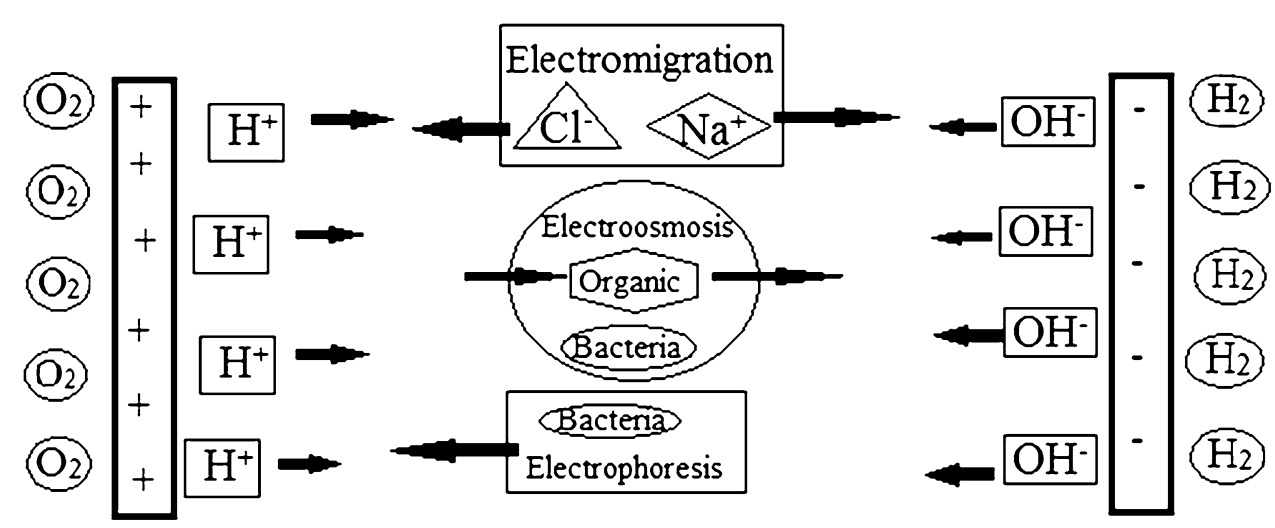


Table 2 Physical and chemical properties of soil

\begin{tabular}{ll}
\hline Soil property & Amount \\
\hline Effective porosity (\%) & 40.3 \\
Air-dried density $\left(\mathrm{g} / \mathrm{cm}^{3}\right)$ & 1.576 \\
Saturated water content $(\%)$ & 25 \\
Liquid limit (\%) & 38 \\
Plastic limit (\%) & 23 \\
TOC $(\%)$ & 1.27 \\
Mg $(\%)$ & 4.47 \\
EC $(\mathrm{ms} / \mathrm{cm})$ & 4.4 \\
Permeability $(\mathrm{cm} / \mathrm{s})$ & $6 \times 10^{-3}$ \\
$\mathrm{TN}(\mathrm{mg} / \mathrm{kg})$ & 79 \\
$\mathrm{TP}(\mathrm{mg} / \mathrm{kg})$ & 18 \\
$\mathrm{pH}$ & 7.6 \\
\hline
\end{tabular}

Kebria 2012). Two steel rods were inserted into electrodes for connecting with the DC power supply. Whatman filter papers (0.42 $\mathrm{mm}$ in diameter, Japan) were used to separate the soil from the electrodes. Each reactor contains about 2,200 $\mathrm{g}$ of the contaminated soil with a moisture content of $25 \%$. Two control reactors $(16 \times 15 \times 10.5 \mathrm{~cm})$ (without electric current), one for each concentration of contamination, were prepared with soil in the same way.

The power supply provided constant DC voltage of $15 \mathrm{~V}$ $(1 \mathrm{~V} / \mathrm{cm})$, which induces the movement of contamination within the soil cell for 8-16 days. During the EK operation, electric current across the soil specimen, $\mathrm{pH}$, temperature, and moisture were monitored every day. Soils were sampled three times. Once at the start of the run from the cathode; center and anode areas of the reactor and from the controls, again once in the middle of test and once the run were completed. The samples were removed with a stainless steel soil corer and were analyzed for moisture content, $\mathrm{pH}$, and PCE concentrations.

Fig. 2 Schematic of EK decontamination process
Analytical methods

Soil samples were analyzed as follows. Moisture content and $\mathrm{pH}$ analyses were carried out on fresh soil. For analysis of moisture content, 5-g subsamples of soil were weighed into evaporating dishes and oven-dried at $105^{\circ} \mathrm{C}$ overnight. Samples were re-weighed after cooling in desiccators, and the percentage moisture content was calculated from the loss in weight (Allen et al. 1974).

Measurements of $\mathrm{pH}$ were taken on 5-g soil samples, suspended in $12.5 \mathrm{ml}$ of $\mathrm{CaCl}_{2}$ (soil: $\mathrm{CaCl}_{2}$ ratio of $1: 2.5$ ). The soil suspensions were shaken for several minutes on a tube shaker and then left to settle for 15 min prior to $\mathrm{pH}$ determination (O'Connor et al. 2003).

The concentration of PCE in the soil was determined according to the following steps. First, $30 \mathrm{ml}$ of $n$-hexane and $3 \mathrm{~g}$ of soil were added to a glass tube and then are shaken on the tube-shaking device for 2 min to extract contamination from soil. After settling suspensions, liquid phase is separated from suspension. The solutions were introduced to Fourier transform infrared spectroscopy (FTIR) in order to determine the residual PCE concentration in the soil.

\section{Results and discussion}

\section{Electric current}

Figure 3 shows the electric current change during the experiments. The electric currents varied in the range between 24-41 and 23-34 mA in Ek-1 \% and Ek-3 \%, respectively.

The variations in electric currents were similar with the results reported by Lim et al. (2004), O'Connor et al. (2003) and Cang (2011). Generally, the electric currents were positively related to the applied voltages, soil EC, soil water

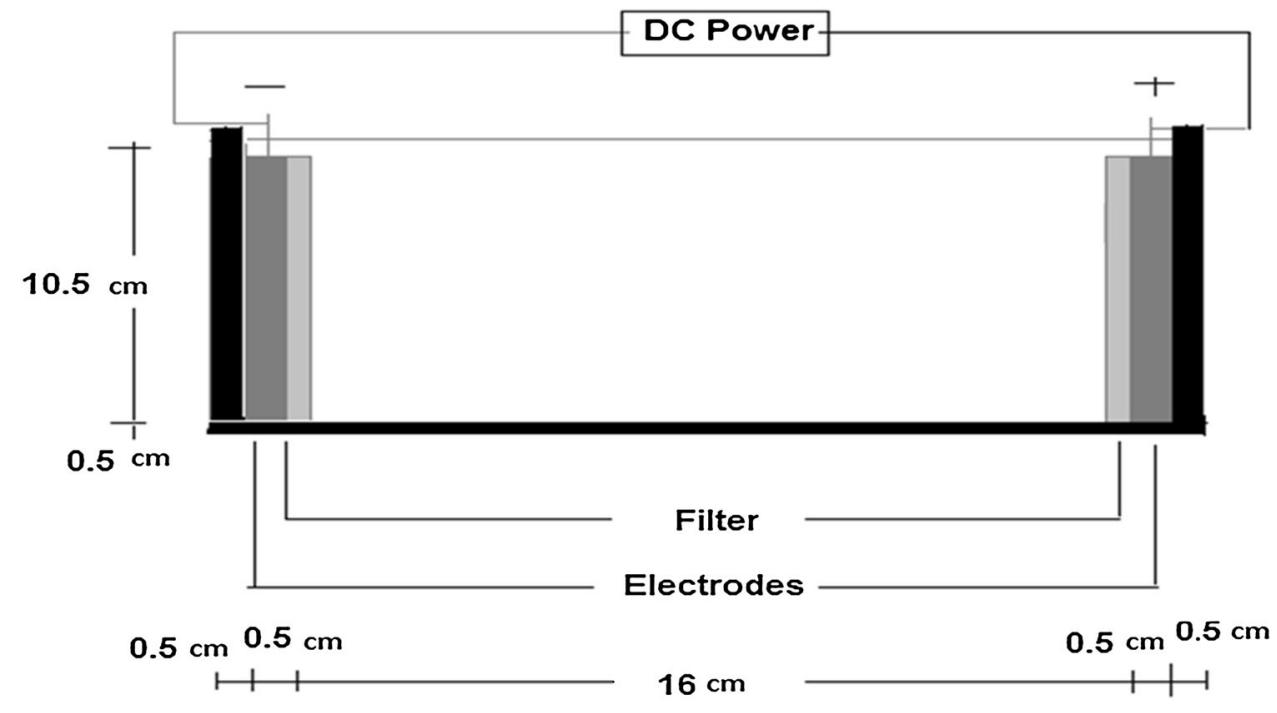




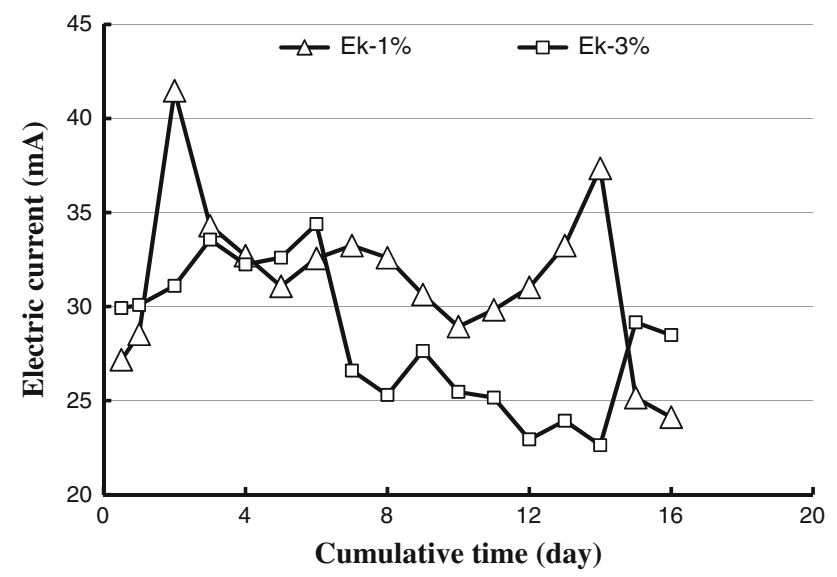

Fig. 3 Changes in electric currents for the different treatments

content, and so on (Acar and Alshawabkeh 1993). In the case of the voltage remains constant at both ends, the potential difference across the soil varies. Establishing an electric field between the electrodes is created mechanisms that cause the movement of ions and pore flow water and rearrange them in the soil. As a result, soil takes a variable resistance; thus, the intensity of the electric current in the sample is changed. The variations in electric currents during electrokinetic processes and the difference in the two contaminated soils can be explained that the electric current is related to the concentration of PCE in soils. In this study, the electric current tends to slowly decrease with time due to increased resistance of the soil. It may be ascribed to mineral dissolution or clogging, precipitation near the cathode, and/or gas formation as a result of electrolysis (which decreases the degree of saturation and thus electrical conductivity).

\section{Change in soil $\mathrm{pH}$}

During the operation of each reactor, there were significant changes in soil pH (Fig. 4). These changes were similar for both test soils.

The soil $\mathrm{pH}$ near the anode decreased, while that near the cathode increased. The soil $\mathrm{pH}$ in anode varied from 7.6 to 5.86 and 7.6 to 5.95 , while the soil $\mathrm{pH}$ in cathode varied from 7.6 to 10.65 and 7.6 to 10.90 in Ek-1 \% and Ek-3 \%, respectively. Upon electric field application, decomposition of water (electrolysis reactions) occurs at the electrodes. The electrolysis reactions generate oxygen gas and hydrogen ions $\left(\mathrm{H}^{+}\right)$due to oxidation at the anode and hydrogen gas and hydroxyl $\left(\mathrm{OH}^{-}\right)$ions due to reduction at the cathode as shown by the following reactions:

At anode (oxidation) : $2 \mathrm{H}_{2} \mathrm{O} \rightarrow \mathrm{O}_{2}+4 \mathrm{H}^{+}+4 \mathrm{e}^{-}$

At cathode (reduction) : $4 \mathrm{H}_{2} \mathrm{O}+4 \mathrm{e}^{-} \rightarrow 2 \mathrm{H}_{2}+4 \mathrm{OH}^{-}$

In particular, acid is produced at the anode and alkaline solution is produced at the cathode; therefore, $\mathrm{pH}$ in the
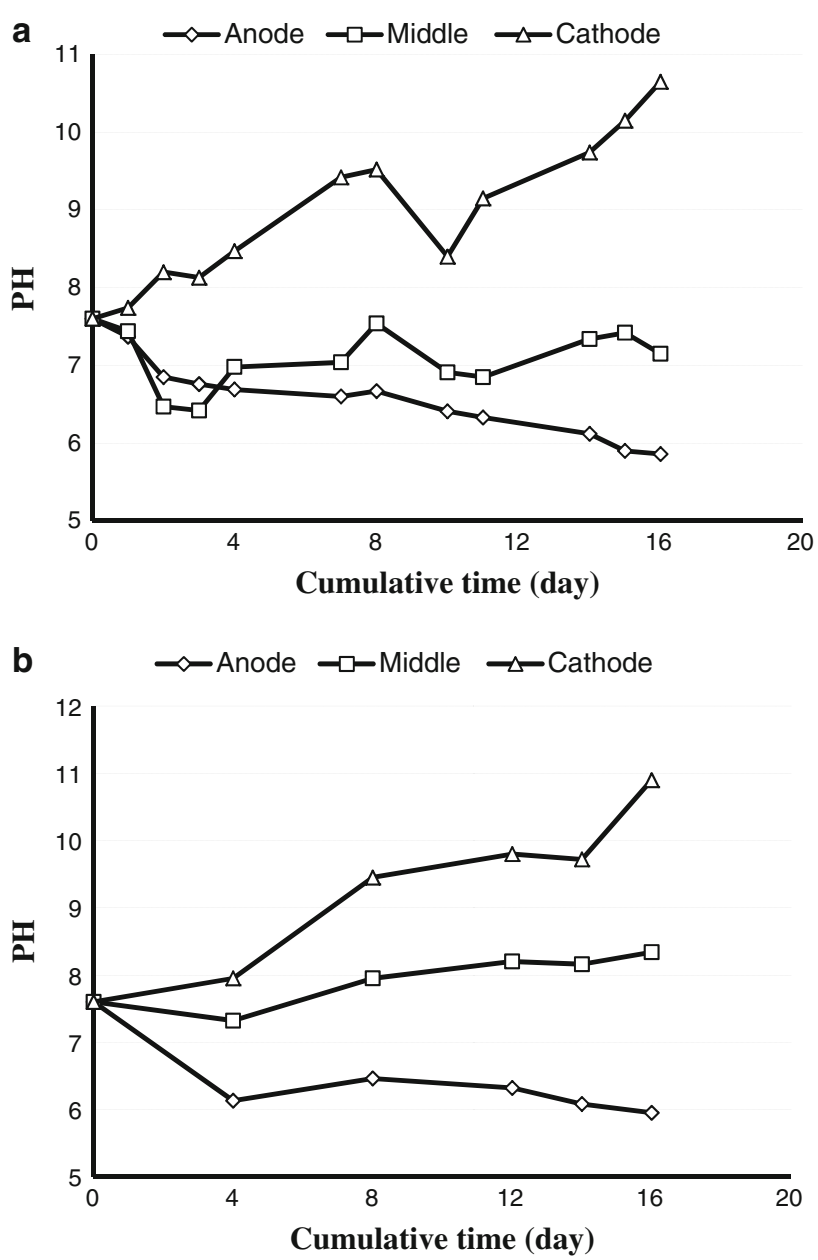

Fig. 4 Change in soil pH during soil sections, Ek-1\% (a) and Ek$3 \%(\mathbf{b})$

cathode is increased, while $\mathrm{pH}$ at the anode is decreased. The migration of $\left(\mathrm{H}^{+}\right)$from the anode and $\left(\mathrm{OH}^{-}\right)$from the cathode into the soil leads to dynamic changes in soil $\mathrm{pH}$ during the initial stages of electric potential application (Reddy and Cameselle 2009a, b). It was reported by O'Conner et al. (2003) and Aboughalma and Schlaak (2008) that the DC electric field might cause the acidification in the anode region and the alkalization in the cathode region, which ascribed to the generation of $\mathrm{H}^{+}$and $\mathrm{OH}^{-}$ions from water electrolysis under DC treatment.

\section{Efficiency of PCE removal}

In this study, the pollutant used not only has a very low solubility, but also is in a non-polar form, and the electric field normally does not affect it. Because of these features of PCE, isolation and movement of PCE across the soil by EK remediation confronted with some limitation. In this study, to overcome this problem, the non-ionic detergent was used, in order to increase the solubility of PCE and to increase the efficiency of remediation. Electroosmotic flow 

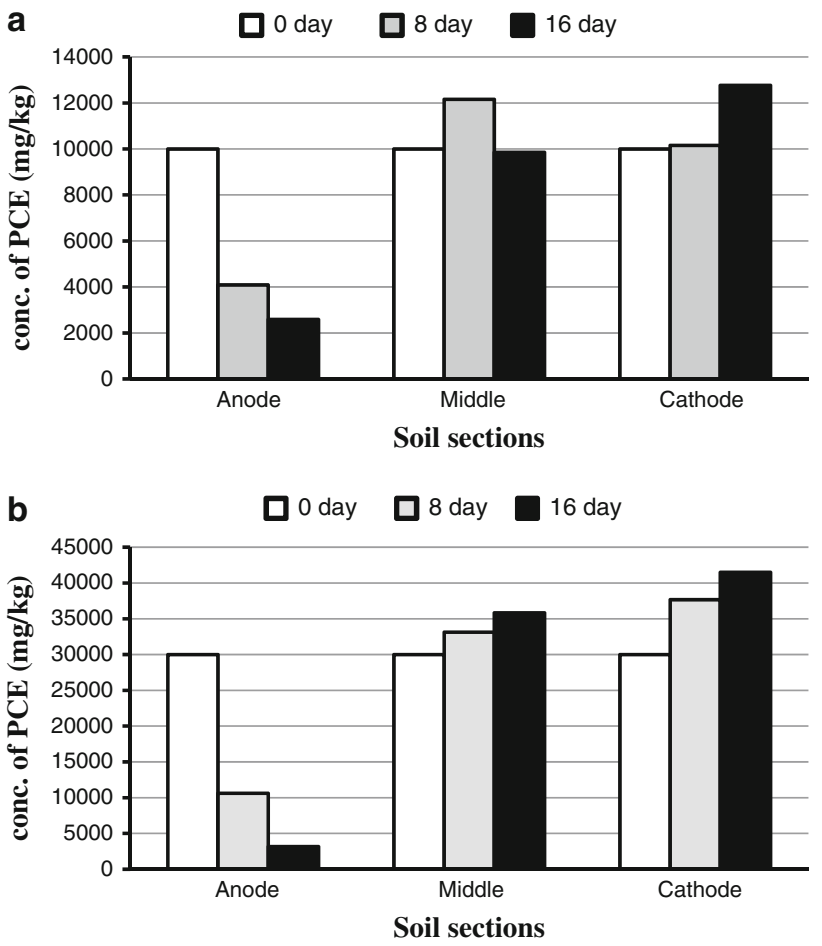

Fig. 5 The distribution of PCE in the soil compartment following the electrokinetic experiments, $1 \%$ (a) and $3 \%$ (b)

occurs during the EK process, which causes the pore flow water to move from the anode to the cathode (Yeung and Gu 2011; Mukhopadhyay et al. 2013). The movement of non-ionic detergent in soil affects PCE. This action occurs by stimulation mechanism (moving of ion). Detergent monomers increase the contact angle between the soil and hydrophobic contaminants and, on the other hand, reduce the surface tension of PCE and soil. Therefore, the main adhesive force of soil and PCE (capillary adhesion force) will be reduced. So, the combination of EK process and detergent causes the movement of PCE in the soil.

The concentration of PCE in the soil compartment after the electrokinetic experiments is shown in Fig. 5.

In these experiments, PCE was nearly completely removed in the section near the anode, because PCE was solubilized by the surfactant and migrated by electroosmotic flow (Jeon et al. 2010), Fig. 5. Surfactant Triton $\mathrm{X}-100$ was transported, by electroosmotic flow (EOF), toward the cathode. The movement of surfactant (Tx-100) enhanced desorption of PCE from the soil and their dissolution into the surfactant Tx-100. As a result, the removal of PCE in anode section increased due to the enhanced electroosmotic flow (Park 2009; Saichek and Reddy 2003). However, the PCE in the section near the cathode was not removed and accumulated. The disposal of PCE in cathode section in uniform electrokinetic process, which is used in this study, is impossible, but in non-uniform electrokinetic process, the disposal of contaminant in cathode section is possible.

In the case when $0.5 \mathrm{gr} / \mathrm{kg} \mathrm{Tx}-100$ soil was used as a surfactant, the zeta potential of the cathode region was negative and the direction of EOF was from the anode to the cathode. The zeta potential of the middle section was nearly zero, and EOF in this region was very slow. Consequently, the removal of PCE in the anode region was high and that of the middle section was moderate, and PCE gets accumulated at the cathode region.

The electroosmotic flow is related to the zeta potential of the soil particle and $\mathrm{pH}$. The zeta potential is generally positive at low $\mathrm{pH}$ and negative at high $\mathrm{pH}$ (Reddy and Cameselle 2009a, b). When Tx-100 was used as the surfactant, the soil $\mathrm{pH}$ increased and the surface charge on the soil was negative. A negatively charged soil surface resulted in a more negative zeta potential and greater electroosmotic flow toward the cathode. In addition, Tx-100 dissolves the organic matter. The surfactant causes the release of the tight matrix of PCE (Yeom and Cox 1996). The hydrocarbons become solubilized in surfactant micelles (Jee et al. 2005). The desorbed PCE was solubilized by surfactant micelles and removed by EOF. Consequently, PCE removal was affected by the amount of EOF and desorption of PCE. Therefore, the major mechanism used for PCE removal was considered to be electroosmosis (Jeon et al. 2010), with the use of Tx-100 as a surfactant enhancing desorption of PCE from the soil.

Figure 5 shows that the distribution of PCE removal near the anode section is high. It can be found that the residual concentration near the cathode was still high. As the EK process lasted for 16 days with $1 \mathrm{~V} / \mathrm{cm}$ applied to the 1 and $3 \%$ system a nearly 74 and $89 \%$ PCE removal was achieved in the vicinity of the anode sections of the soil. A total PCE removal of 16 and $11 \%$ was achieved for Ek-1 \% and Ek-3 \%, respectively. It justified that because of the bacteria cannot be alive in presence of electric field in anode and cathode section, the efficiency of PCE removal was low and only the motion of PCE was carried by EK process. As described for the EK process, a greater removal of PCE in anode section is associated with greater EOF and less electric resistance across the reactor.

The control experiments showed the removal of PCE, 34 and $29 \%$, respectively. Soil naturally due to properties such as physical property (existence of pores), adsorption properties (existence of opposite charges) and biological properties (existence of bacteria), has assimilative property and is capable that to extant naturally remove the PCE.

\section{Conclusion}

This study presented the performance of an EK process in treating artificially contaminated clay soil using non-ionic 
surfactant as the processing fluid. Results indicate that the electroosmotic advection is a primary transport mechanism responsible for the movement and removal of PCE from clay. Increasing of time can enhance the PCE movement and removal efficiency. A better PCE removal from anode section was observed for the Ek-1 \% than for the Ek-3 \%. This study shows that the EK process is a feasible in situ technology for transporting PCE from clayey soil using a DC.

\section{Acknowledgement}

The authors gratefully acknowledge Babol Noshirvani University of Technology for financial supports and Mazandaran Agricultural and Natural Resources Research Center for technical supports and assistance.

\section{References}

Aboughalma H, Schlaak M (2008) Electrokinetic enhancement on phytoremediation in $\mathrm{Zn}, \mathrm{Pb}, \mathrm{Cu}$ and $\mathrm{Cd}$ contaminated soil using potato plants. J Environ Sci Health 43(8):926-933

Acar Y, Alshawabkeh AN (1993) Principles of electrokinetic remediation. Environ Sci Technol 27(13):2638-2647

Adams RH, Cuzman FJ, Domingues VI (2013) Field-scale evaluation of chemical biological stabilization process for the remediation of hydrocarbon-contaminated soil. Environ Sci Technol. doi:10. 1007/s13762-013-0321-1

Allen SE, Grimshaw HM, Parkinson JA, Quarmby C (1974) Chemical analysis of ecological materials. Blackwell Scientific Publications, Oxford. $\mathrm{x}+565 \mathrm{pp}$

Arjoon A, Olaniran AO, Pillary B (2013) Co-Contamination of water with chlorinated hydrocarbons and heavy metals: challenges and current bioremediation strategies. Environ Sci Technol 10(2):395-412

Bruell C, Segall B, Walsh M (1992) Electro-osmotic removal of gasoline hydrocarbons and TCE from clay. J Geotech Environ Eng 118(1):68-83

Cang L (2011) Effects of electrokinetic-assisted phytoremediation of a multiple-metal contaminated soil on soil metal bioavailability and uptake by Indian mustard. Sep Purif Technol 79(2):246-253

Chung H, Lee M (2007) A new method for remedial treatment of contaminated clayey soils by electrokinetics coupled with permeable reactive barriers. Electrochim Acta 52(10):3427-3431

Fischer A, Rowan E, Spalding F (1987) VOCs in ground water influenced by large scale withdrawals. Ground Water 25(4):407-414

Freedman DL, Gossett JM (1989) Biological reductive dechlorination of tetrachloroethylene and trichloroethylene to ethylene under methanogenic conditions. App Environ Microbiol 55(9):2144-2151

Gan S, Lau EV, Ng HK (2009) Remediation of soils contaminated with polycyclic aromatic hydrocarbons (PAHs). J Hazard Mater 172:532-549

Gholami M, Yousefi Kebria D (2012) The comparison of phytoremediation and electrokinetic methods in remediation of petroleum hydrocarbons contaminated soil. The GEOMATE International Society 978-4-9905958-1-4 C3051, pp 808-811

Ho SV, Athmer C, Shridan PW, Hughes BM, Orth R, Meckenzie D, Brodsky PH, Shapiro A, Thornton R, Salvo J, Schultz D, Landis
R, Griffith R, Shoemaker S (1999) The Lasagna technology for in-situ soil remediation. Environ Sci Technol 33(7):1086-1091

Hunter R (1981) Zeta potential in colloid science. Academic Press, London and New York xi, $386 \mathrm{p}$

Jee SH, Ko SO, Jang HN (2005) Effects of surfactants on the fenton degradation of phenanthrene in contaminated sediments. Environ Eng Res 10(3):138-143

Jeon C, Yang J, Kim K, Baek K (2010) Electrokinetic removal of petroleum hydrocarbon from residual clayey soil following a washing process. Clean 38(2):189-193

Khodadadi A, Yousefi D, Ganjidoust H, Yari M (2011) Bioremediation of diesel-contaminated soil using Bacillus sp. (strain TMY2) in soil by uniform and non-uniform electro kinetic technology field. J Toxic Environ Health Sci

Lim J, Salido A, Butcher D (2004) Phytoremediation of lead using Indian mustard Brassica juncea with EDTA and electronics. Microchem J 76(1):3-9

Mitchell JK (1993) Fundamentals of soil behavior. Wiley, New York, 422 P./28 cm

Mukhopadhyay S, Hashim MA, Allen M, Sencupta B (2013) Arsenic removal from soil with high iron content using a natural surfactant and phosphate. Environ Sci Technol. doi:10.1007/ s13762-013-0441-7

O'Connor C, Lepp NW, Edwards R, Sunderland G (2003) The combined use of electrokinetic remediation and phytoremediation to decontaminate metal-polluted soils: a laboratory-scale feasibility study. Environ Monit Assess 84(1):141-158

Park S (2009) Electrokinetic remediation of contaminated soil with waste-lubricant oils and zinc. J Hazard Mater 169(1):1168-1172

Reddy K, Cameselle C (2009a) Electrochemical remediation technologies for polluted soils, sediments and groundwater. Wiley, New York

Reddy K, Cameselle C (2009b) Overview of electrochemical remediation technologies. Wiley, New York

Reddy K, Saichek R (2003) Effect of soil type on electrokinetic removal of phenanthrene using surfactants and cosolvents. J Environ Eng 129(4):336-346

Saichek R, Reddy K (2003) Effect of pH control at the anode for the electrokinetic removal of phenanthrene from kaolin soil. Chemosphere 51(4):273-287

Weng CH, Lin YH, Hsieh YH (2000) Electrokinetic remediation of trichloroethylene contaminated kaolinite. J Chin Inst Environ Eng 10(4):279-289

Yang GCC, Long YW (1999) Removal of degradation of phenol in a saturated flow by in situ electrokinetic remediation and Fentonlike process. J Hazard Mater 69(3):259-271

Yeom I, Cox CD (1996) Kinetic aspects of surfactant solubilization of soil-bound polycyclic aromatic hydrocarbons. J Environ Sci Technol 30(5):1589-1595

Yeung AT, Corapcioglu MY (1994) Electrokinetic flow processes in porous media and their applications. Adv Porous Media 2:309-339

Yeung AT, Gu YY (2011) A review on techniques to enhance electrochemical remediation of contaminated soils. J Hazard Mater 195:11-29

Yeung AT, Hsu C, Menon R (1996) EDTA-enhanced electrokinetic extraction of lead. J Geotech Eng 122(8):666-673

Zhang T, Zou H, Ji M, Li X, Li L, Tang T (2013) Enhanced electrokinetic remediation of lead-contaminated soil by complexing agent and approaching anodes. J Environ Sci Technol. doi:10.1007/s11356-013-2274-9 